\title{
Investigation of Water Aeration Based on Digital Image Processing
}

\author{
Adelė VAIDELIENE**, Gintautas MILIAUSKAS** \\ *Aleksandras Stulginskis University, Studentu 11, Kaunas, LT-53361, Lithuania, E-mail: Adele.Vaideliene@asu.lt \\ **Kaunas University of Technology, K. Donelaičio 20, Kaunas, LT-44239, Lithuania, E-mail: gimil@ktu.lt
}

cross $^{\text {ref }}$ http://dx.doi.org/10.5755/j01.mech.24.3.19525

\section{Introduction}

The air-water interactions are highly dependent on ambient conditions [1-5]. In addition, the air-water interactions are greatly effected by the type of flow - laminar or turbulent [6-10]. Turbulence stimulates generation of air bubbles and their entrapment in water [11-14]. First experiments dealing with entrapment of air bubbles were undertaken in the middle of the twentieth century [15-16]. At that time entrapment process was viewed as a diffusion of air bubbles in water [17-22]. Now it is known that it was a great oversimplification. Presently it is known that many other mechanisms affect entrapment of air bubbles. For example, water flowing through the weirs and then forced through the turbines create mix with air and create turbulent mixtures of air bubbles and water droplets [23-29]. Resulting mixtures are commonly called "white water" due to its visual effect.

Free falling vertical water jets hitting open air-water interfaces can create similar conditions. Here, this type of mechanism was studied experimentally. A non-contact optical measuring system was employed in the experimental part of the study. The referenced experimental technique was used to determinate aeration as a function of air-water interaction at various depths and widths.

\section{The experimental method of air bubble concentra- tion measurement}

Gas circulation through air-water interface can be treated as a process of diffusion. This circulation occurs in uniforms as well as in turbulent flows. Under turbulent conditions diffusion process creates very thin marginal watery layer [30]. Gradient of gas concentration in this layer determines gas flux value. Some factors for example such as an undulation of a free surface and turbulence slenderize mentioned layer and, in this way, increases gradient of gases concentration and gases transfer through interface. Water flow vertically falling in smooth water surface stimulates air entrainment in the depth of water. Air bubbles entrained in water highly increases the rate of gas transfer through airwater interface because air bubbles destroy diffusion substratum and contacts liquid directly with increased area [3132]. Many researchers [33-35] were investigating this process as a steady (Fig. 1), however dynamics of air bubbles entrainment in natural processes is even more important.

Experimentation utilized digital processing of images registered by the Canon Power Shot SX20IS camera connected to computer.

The companion experiment was performed under laboratory conditions with a free vertical hitting the jet water surface in a transparent cylindrical vessel

The setup of experiment is shown in the Fig. 2. Dimensions of the cylinder were: diameter $-18 \mathrm{~cm}$ and

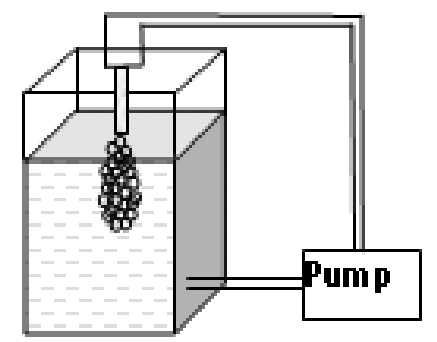

Fig. 1 Layout of air bubbles entrainment with steady process

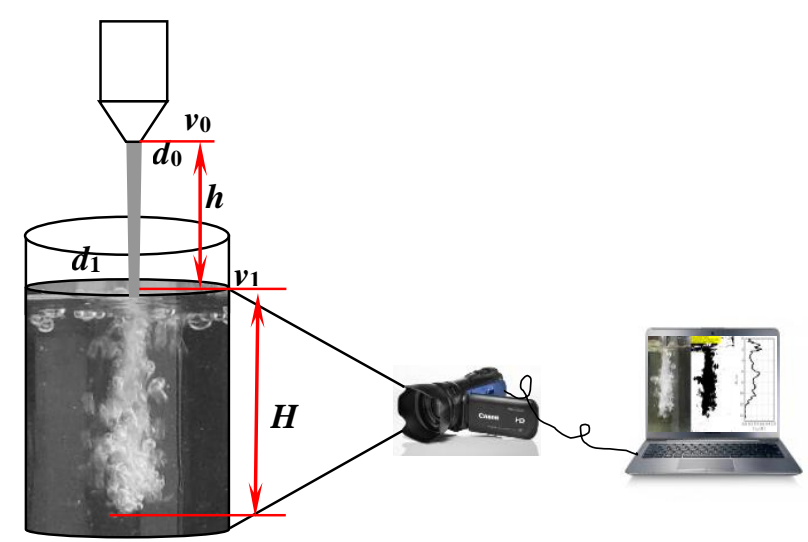

Fig. 2 Setup of experiment

depth $-18.5-\mathrm{cm}$.

Diameter of the jet nozzle was $d_{0}$, initial velocity of jet $v_{0}=0, v_{1}$ - velocity of the jet at the moment of its contact with the water surface, $h$ - the height of the falling jet i.e. distance from the nozzle tip to the water surface. $h$ was varied in steps of $0.25 \mathrm{~m}$ from $h=0.25 \mathrm{~m}$ to $h=1 \mathrm{~m}, H$ - air penetration depth $(\mathrm{m})$. Also, the jet nozzle diameter $d_{0}$ was varied from $0.003 \mathrm{~m} \div 0.008 \mathrm{~m}$. Additional information is given in the Table 1. All experiments were performed pouring described vessel a fixed volume of water $V$. Average amount of water $Q_{w}\left(\mathrm{~m}^{3} / \mathrm{s}\right)$ flowing through the jet nozzle can be calculated as:

$$
Q_{w}=\frac{V}{t}
$$

where: $t$ is time of water pouring. Also, $Q_{w}$ can be calculated as:

$$
\left\{\begin{array}{l}
Q_{w}=v_{0} \cdot \pi \cdot\left(\frac{d_{0}}{2}\right)^{2} \\
Q_{w}=v_{1} \cdot \pi \cdot\left(\frac{d_{1}}{2}\right)^{2}
\end{array}\right.
$$


Eq. (1) give:

$\frac{v_{1}}{v_{0}}=\frac{d_{0}^{2}}{d_{1}^{2}}$.
From the energy conservation law it follows:

$$
v_{1}^{2}=v_{0}^{2}+2 g \cdot h,
$$

where: $g$ is free fall acceleration, $d_{0}$ and $d_{l}$ are shown Fig. 2 .

Table 1

Initial Data of Experiments

\begin{tabular}{|l|l|l|l|l|l|l|l|l|l|l|l|}
\hline \multicolumn{3}{|c|}{$d_{0}=0.003 \mathrm{~m} ; Q_{w}=1.5543 \cdot 10^{-5} \mathrm{~m}^{3} / \mathrm{s}$} & \multicolumn{3}{c|}{$d_{0}=0.004 \mathrm{~m} ; Q_{w}=2.2382 \cdot 10^{-5} \mathrm{~m}^{3} / \mathrm{s}$} & \multicolumn{3}{c|}{$d_{0}=0.005 \mathrm{~m} ; Q_{w}=3.8149 \cdot 10^{-5} \mathrm{~m}^{3} / \mathrm{s}$} \\
\hline$h, \mathrm{~m}$ & $v_{1}, \mathrm{~m} / \mathrm{s}$ & $d_{1}, \mathrm{~m}$ & $F r_{1}$ & $h, \mathrm{~m}$ & $v_{1}, \mathrm{~m} / \mathrm{s}$ & $d_{1}, \mathrm{~m}$ & $F r_{1}$ & $h, \mathrm{~m}$ & $\begin{array}{l}v_{1}, \\
\mathrm{~m} / \mathrm{s}\end{array}$ & $d_{1}, \mathrm{~m}$ & $F r_{1}$ \\
& & & & & & & & & & & \\
0.25 & 2.2 & 0.0026 & 13.8 & 0.25 & 2.2 & 0.0036 & 11.7 & 0.25 & 2.2 & 0.0047 & 10.3 \\
0.5 & 3.1 & 0.0023 & 20.6 & 0.5 & 3.1 & 0.003 & 18.1 & 0.5 & 3.1 & 0.004 & 15.7 \\
0.75 & 3.8 & 0.0101 & 26.7 & 0.75 & 3.8 & 0.0027 & 23.4 & 0.75 & 3.8 & 0.0036 & 20.2 \\
1.0 & 4.4 & 0.0097 & 31.6 & 1.0 & 4.4 & 0.0025 & 28.1 & 1.0 & 4.4 & 0.0033 & 24.5 \\
\hline
\end{tabular}

\begin{tabular}{|l|lll|l|l|l|l|}
\hline \multicolumn{4}{|l|}{$d_{0}=0.007 \mathrm{~m} ; Q_{w}=7.9856 \cdot 10^{-5} \mathrm{~m}^{3} / \mathrm{s}$} & \multicolumn{3}{c|}{$d_{0}=0.008 \mathrm{~m} ; Q_{w}=1.0778207 \cdot 10^{-4} \mathrm{~m}^{3} / \mathrm{s}$} \\
\hline$h, \mathrm{~m}$ & $v_{1}, \mathrm{~m} / \mathrm{s}$ & $d_{1}, \mathrm{~m}$ & $F r_{1}$ & $h, \mathrm{~m}$ & $v_{1}, \mathrm{~m} / \mathrm{s}$ & $d_{1}, \mathrm{~m}$ & $F r_{1}$ \\
\hline 0.25 & 2.2 & 0.0068 & 8.5 & 0.25 & 2.2 & 0.0079 & 7.9 \\
0.5 & 3.1 & 0.0057 & 13.1 & 0.5 & 3.1 & 0.0067 & 12.1 \\
0.75 & 3.8 & 0.0052 & 16.8 & 0.75 & 3.8 & 0.006 & 15.7 \\
1.0 & 4.4 & 0.0048 & 20.3 & 1.0 & 4.4 & 0.006 & 18.1 \\
\hline
\end{tabular}

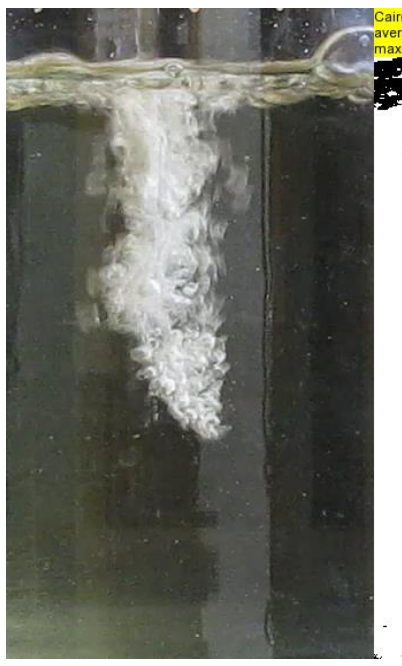

Fig. 3 Analyze of image received with digital camera $\left(d_{0}=0.003 \mathrm{~m}, h=0.5 \mathrm{~m}, v_{1}=3.1 \mathrm{~m} / \mathrm{s}, d_{1}=0.0023\right.$ $\left.\mathrm{m}, Q_{w}=1.5543 \cdot 10^{-5} \mathrm{~m}^{3} / \mathrm{s}, F r_{1}=20.6\right)$. At the left white view - air bubbles, at the right air bubbles presented with black

Measurement technique that we are here presenting is explained in the Fig. 3. At the left side the real image of the air bubbles and water droplets mixture is shown. At the right side the modified image, with the air bubbles changed to the black spots is presented. Visual analysis of the left image shows that the air bubbles are much brighter than the background. This feature allows evaluation of the air bubble concentration in the water.

Real white air bubbles view is converted to the conditional grey scale image. The grey scale image consists of large scale shades of grey, varying from black at the lowest intensity to white at the highest intensity.

Range of binary values on grey scale is from 0 for black to 255 for white (Fig. 4). The right side image of the Fig. 6 is composed assuming that if a pixel value is $>145$ it is taken as black and if $<145$ it is taken as white. Image processing and analysis [36] was made using the Python code. Our code evaluates how the air concentration in the water is distributed in depth and in width. The air concentration is calculated as the ratio of black pixels in each row and column of the modified black and white picture.

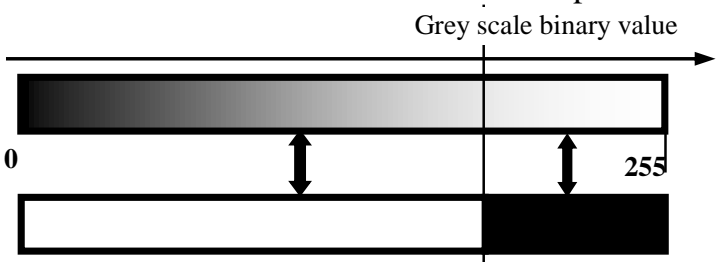

Fig. 4 Evaluation of pixels values [37]

This code allows evaluation of accuracy of processing. Quantitative image quality parameters were evaluated by determination following errors [38-39]:

a) Normalized Absolute Error $\left(E_{\text {norm }}\right)$ :

$$
E_{n o r m}=\frac{\sum_{i=0}^{s-1} \sum_{j=0}^{l-1}|x(i, j)-\tilde{x}(i, j)|}{\sum_{i=0}^{s-1} \sum_{j=0}^{l-1} x(i, j)}
$$

where: $x(i, j)$ is the color value of the original image at $(i, j)$, $\tilde{x}(i, j)$ is the color value of the encoding image, $s, 1$ are maximal indices of row and column pixels.

b) Laplacian Mean Square Error $\left(E_{\text {Lapl }}\right)$ :

$$
E_{\text {Lapl }}=\frac{\sum_{i=1}^{s-2} \sum_{j=1}^{l-2}[L(x(i, j))-L(\tilde{x}(i, j))]^{2}}{\sum_{i=1}^{s-2} \sum_{j=1}^{l-2} L^{2}(x(i, j))},
$$

where:

$$
L(x(i, j))=x(i-1, j)+x(i+1, j)+x(i, j-1)+x(i, j+1)-4 x(i, j) .
$$

The larger $E_{\text {Lapl }}$ value means poorer image quality. 


\section{Experimental results and discussion}

As can be seen from fig. 5, concentration of air entrained in depth varies. Amount of air entrained depends on diameter of nozzle $d_{0}$, height $h$, diameter $d_{1}$ of jet, and jet velocity $v_{1}$. Fig. 5 shows the time sequence of a water jet initially hitting a free water surface when the nozzle exit velocity is $v_{0}=0.0 \mathrm{~m} / \mathrm{s}, v_{1}=2.2 \mathrm{~m} / \mathrm{s}$, the jet falling height is $0.25 \mathrm{~m}, Q_{w}=1.5543 \cdot 10^{-5} \mathrm{~m}^{3} / \mathrm{s}, d_{0}=0.003 \mathrm{~m}$,

$d_{1}=0.0026 \mathrm{~m}$. The camera started recording before jet hit the free surface to assurance entrapping the whole process of initial hit. Fig. 5, a demonstrates water surface deformation by falling jet and air entrainment start. At the time $t=10 \mathrm{~ms}$ single air bubble is entrained in deeper water lay- ers. It develops quickly and at $t=21 \mathrm{~ms}$ cone shape cavity forms (Fig. 5, b), that later $(t=21 \mathrm{~ms})$ becomes cylinder shape (Fig. 5, c). As can be seen from Fig. 5, i amount of air entrained in water increases and at time $t=3 \mathrm{~s}$ reaches its maximum value. At this moment water jet was switched of. At the left side of each figure the real image of the experiment is presented while in the middle of figure the digital image of air bubbles and water is shown. Air bubbles correspond to black scale and water - to the white. Graph shows distribution of air concentration to the depth as well as to the width. At time moment $t=3$ the maximum entrainment depth $(H=0.11 \mathrm{~m})$ was reached. Velocity of air entrainment was $0.0367 \mathrm{~m} / \mathrm{s}$.
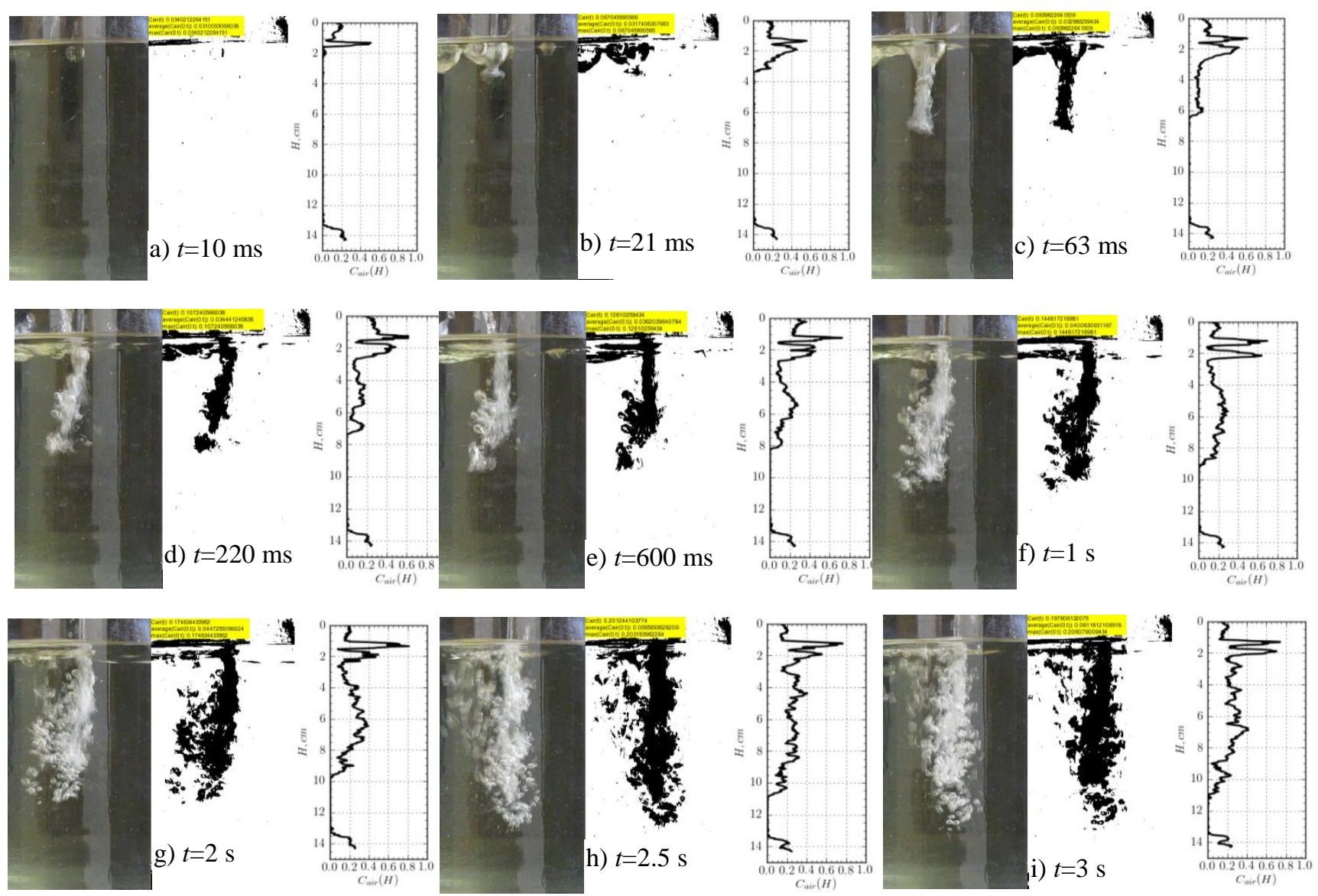

Fig. 5 Developing of entrained air distribution at different times, when $d_{0}=0.003 \mathrm{~m}, h=0.25 \mathrm{~m}, v_{1}=2.2 \mathrm{~m} / \mathrm{s}, d_{1}=0.0026 \mathrm{~m}$, $Q_{w}=1.5543 \cdot 10^{-5} \mathrm{~m}^{3} / \mathrm{s}, F r_{1}=13.8$
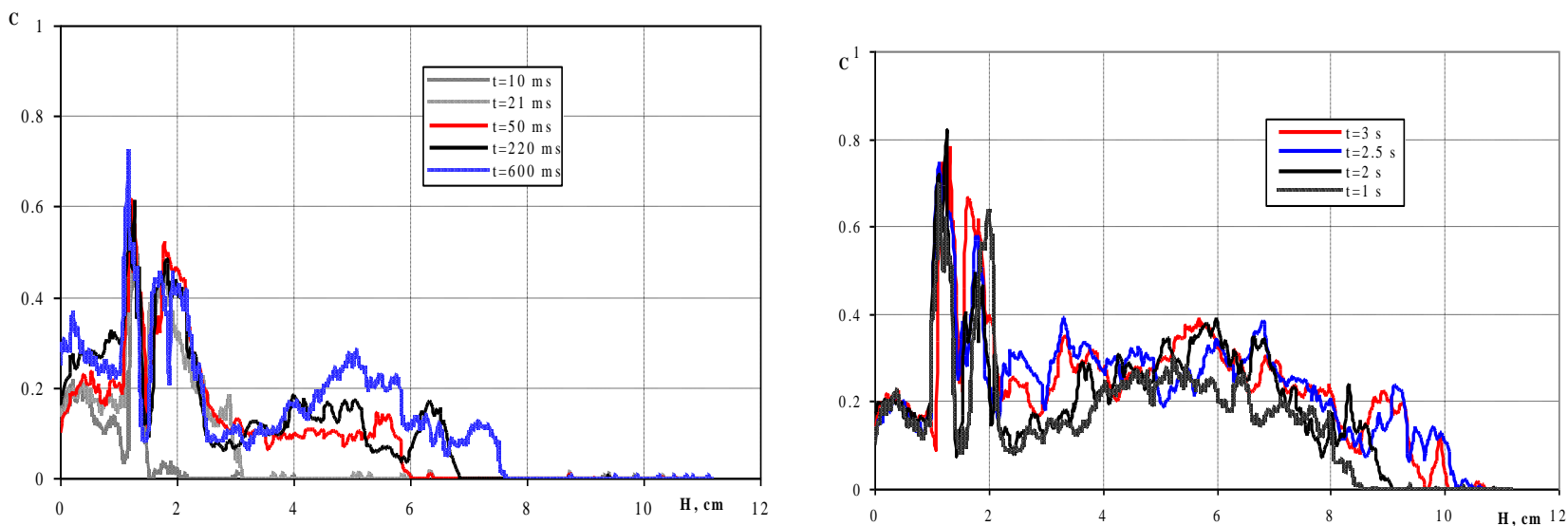

Fig. 6 Change of air entrained in the depth at different time moments, when $d_{0}=0.003 \mathrm{~m}, \mathrm{~h}=0.25 \mathrm{~m}$ 
Fig. 6 demonstrates distribution of air concentration in the depth at the different moments of time. Falling water flow was switched off when $(t=3 \mathrm{~s})$ amount of air entrained reached maximal value. Until water is falling down entrainment of air bubbles and their removal acts simultaneously. Therefore two maxima form. First maxima is determined not only by air entrainment and its removal, but also by water sputters sprayed due to jet hit in water surface. These sputters can evaporate or fall back to the surface of water. Descended water sputters can knock out new water sputters or be absorbed by water.

\section{Conclusions}

1. Initial conditions of air bubbles and water droplets mixing determine dynamics of this process that on its own turn determine amount of air bubbles entrained in water.

2. The experimental method of air bubble concentration measurement is based on digital image processing.

3. Dynamics of air bubbles and water droplets mixing can be visualized and analyzed by means of digital images processing.

4. Analyse of images taken at many different moments of mixture developing allows determine amount of air entrained dependences on many parameters, and first of all on height of water flow fall and on nozzle parameters.

\section{References}

1. Ichiyanagi, M.; Tsutsui, I.; Kakinuma, Y.; Sato, Y.; Hishida, K. 2012. Three-dimensional measurement of gas dissolution in gas-liquid microchannel flow, Intern. J. of Heat and Mass Transfer 55: 2872-2878. http://dx.doi:10.1016/j.ijheatmasstransfer.2012.02.009.

2. McGillis, W. R.; Dacey, J. W. H.; Ware, J. D.; Ho, D. T.; Bent, J. T.; Asher, W. E.; Zappa, C. J.; Raymond, P. A.; Wanninkhof, R.; Komori, S. 2007. Air-water flux reconciliation between the atmospheric $\mathrm{CO}_{2}$ profile and mass balance techniques, Garbe C.S., Handler R.A, Jahne B. (editors), In Transport at the air-sea interface: Measurements, models and parameterizations. Springer: Verlag. 1-15.

3. Deswal, S.; Verma, D.V.S. 2007. Air-Water Transfer with Multiple Plun-ging Jets. Water Qual. Res. J. Canada 42: 295-302. https://doi.org/10.2166/wqrj.2007.031.

4. Alves, S.S.; Maia, C.I.; Vasconcelos, J.M.T. 2004. Gas-liquid mass transfer coefficient in stirred tanks interpreted through bubble contamination kinetics, Chemical Engineering and Processing 43: 823-830. https://doi.org/10.1016/S0255-2701(03)00100-4.

5. Mölder, E.; Tenno, T.; Tenno T. 2009. Reseach of oxygen mass transfer thought the air-water surface at low bulk concentrations of surfactants, Proceedings of Estonian Academy of Sciences. 58: 132-136. https://doi.org/10.3176/proc.2009.2.05.

6. Baawain, M.S.; El-Din, M.G.; Smith, D.W. 2012. Characterizing two inclined circular water jets plunging into an aeration tank, Intern. J. of Multiphase Flow 40: $158-165$ http://dx.doi:10.1016/j.ijmultiphaseflow.2011.10.012.

7. Toombes, L.; Chanson H. 2008. Interfacial aeration and bubble count rate distributions in a supercritical flow past a backward-facing step, Intern. J. of Multiphase Flow 34: 427-436.

http://dx.doi:10.1016/j.ijmultiphaseflow.2008.01.005.

8. Tsoukala, V.K.; Moutzouris, C.I. 2008. Gas transfer under breaking waves: experiments and improved vorticity-based model, Ann. Geograph. 26: 2131-2142. http://dx.doi:10.5194/angeo-26-2131-2008.

9. Donelan, M.; Wanninkhof R. 2002. Gas transfer at water surfaces-components and issues, Geophysical Monograph 127, Gas transfer at Water Surfaces: 1-10. http://dx.doi: 10.1029/GM127p0001.

10. Kim, H.; Rao, P.S.C; Annable, M.D. 1999. Gaseous Tracer Technique for Estimating Air-Water Interfacial Areas and Interface Mobility, Soil Sci. Soc. Am. 63: $1554-1560$ http://dx.doi:10.2136/sssaj1999.6361554x.

11. Fuster, D.; Agbaglah, G.; Josserand, C.; Popinet, S.; Zaleski, S. 2009. Numerical simulation of droplets, bubbles and waves: state of the art, Fluid Dyn. Res 41: $1-24$. http://dx.doi.org/10.1088/0169-5983/41/6/065001.

12. Wang, F.-Y.; Xu, L. 2012. Derivative Formula and applications for Hyperdissipative Stochastic NavierStokes/Burgers Equations, Infin. Dimens. Anal. Quantum. Probab. Relat. Top 15: 1-19. http://dx.doi.org/ 10.1142/S0219025712500208.

13. Rafiq, M.; Ahmed, M.O.; Ahmed, S.; Siddique, R.; Pervaiz ,A. 2011. Some Finite Difference Methods for One Dimensional Burger's Equation for Irrotational Incompressible Flow Problem, Pakistan Journal of Engineering \& Applied Sciences 9: 13-16.

14. Van der Burgt, M.J. 2004. Top hat: a smart way to get over 60\% efficiency in simple cycle, Modern Power Systems: 19-25.

15. Sande, E.; Smith, J. M. 1975. Mass transfer from plunging water jets, Chemical Eng. J. 10: 225-233. https://doi.org/10.1016/0300-9467(75)80041-4.

16. Squires, K. D.; Eaton, J. K. 1991. Preferential concentration of particles by turbulence, Phys. Fluids A 3: 1169-1178. https://doi.org/10.1063/1.858045.

17. Liang, J.-H.; McWilliams, J. C.;Sullivan, P. P; Baschek, B. 2011. Modeling bubbles and dissolved gases in the ocean, J. of Geophysical Rresearch 116: 1-17. https://doi.org/10.1029/2010JC006579.

18. Kowal, J. J; Turchan, A.; Heller, K.; Brenizer, J.; Mench ,M. M. 2006. Liquid water storage, distribution, and removal from diffusion media in PEFCS, Journal of the Electrochemical Society 153(10): 971. https://doi.org/10.1149/1.2258049.

19. Josserand, C.; Zaleski, S. 2003. Droplet splashing on a thin liquid film, Phys. Fluids 15: 1650-1657. https://doi.org/10.1063/1.1572815.

20. Fuster, D.; Bagué, A.; Boeck, T.; Moyne, Le L.; Leboissetier, A.; Popinet, S.; Ray, P.; Scardovelli, R.; Zaleski, S. 2009. Simulation of primary atomization with an octree adaptive mesh refinement and VOF method, Int. J. of Multiphase Flow 35: 550-565. https://doi.org/10.1016/j.ijmultiphaseflow.2009.02.014.

21. Azimi, A.H.; Zhu ,D.Z.; Rajaratnam, N. 2012. Computational investigation of vertical slurry jets in water, Int. J. of Multiphase Flow 47: 94-114. http://dx.doi:10.1016/j.ijmultiphaseflow.2012.07.002. 
22. Lima Neto, I.E.; Zhu, D.Z.; Rajaratnam, N. 2008. Effect of tank size and geometry on the flow induced by circular bubble plumes and water jets, J. Hydraul. Eng. ASCE: 134: 833-842.

https://doi.org/10.1061/(ASCE)07339429(2008)134:6(833).

23. Stagonas, D.; Warbrick, D.; Muller, G.; Magagna, D. 2011. Surface tension effects on energy dissipation by small scale, experimental breaking waves, Coastal Engineering 58: 826-836. https://doi.org/10.1016/j.coastaleng.2011.05.009.

24. Kucukali, S.; Chanson, H. 2008. Turbulence measurements in the bubbly flow region of hydraulic jumps, Experimental Thermal and Fluid Science, 33(1): 41-53. https://doi.org/10.1016/j.expthermflusci.2008.06.012.

25. Hoqua, A.; Aoki, S. 2008. Air entrainment and associated energy dissipation in steady and unsteady plunging jets at free surface, Applied Ocean Research 30: 37-45. https://doi.org/10.1016/j.apor.2008.03.004.

26. Chanson, H.; Brattberg, T. 2000. Experimental study of the air-water shear flow in a hydraulic jump, International Journal of Multiphase Flow 26: 583-607. https://doi.org/10.1016/S0301-9322(99)00016-6.

27. Murzyn, F.; Chanson, H. 2009. Free-surface fluctuations in hydraulic jumps: Experimental observations, Experimental Thermal and Fluid Science, 33(7): 10551064. https://doi.org/10.1016/j.expthermflusci.2009.06.003.

28. Chanson, H.; Gonzalez, C.A. 2005. Physical modeling and scale effects of air-water flows on stepped spillways, Journal of Zhejian Universitety SCI 6A(3): 243-250. https://doi.org/10.1631/jzus.2005.A0243.

29. Gonzalez, C.A.; Chanson, H. 2005. Interactions between Cavity Flow and Main Stream Skimming Flows: an Experimental Study, Can Jl of Civ. Eng., 31(1): 3344.

https://doi.org/10.1139/103-066.

30. Li, W.; Yang, K.; Xia, M.; Rao, J.; Zhang, W. 2009. Influence of characteristics of micro-bubble clouds on backscatter lidar signal, Optical Express 17(20): 1777217783. https://doi.org/10.1364/OE.17.017772.

31. Chanson, H. 2010. Convective transport of air bubbles in strong hydraulic jumps, Int. J. of Multiphase Flow 36: 798-814. https://doi.org/10.1016/j.ijmultiphaseflow.2010.05.006.

32. Malinowski, S. P. 2007. Turbulent mixing of cloud with the environment: Two - phase evaporating flow. Numerical simulations, laboratory experiments and field measurements, J. theoretical and applied mechanics 45: 587601.
33. Aulisa, E.; $\quad$ Manservisi, S.; $\quad$ Scardovelli, R.; Zaleski, S. 2007. Interface reconstruction with least-squares fit and spulit advection in three-dimensional Cartesian geometry, J. Of Computational Physics 225: 2301-2319. https://doi.org/10.1016/j.jcp.2007.03.015.

34. Fuster, D.; Colonius, T. 2011. Modeling bubble clusters in compressible liquids, J. of Fluid Mechanics 688: 352-389. https://doi.org/10.1017/jfm.2011.380.

35. Chanson, H. 2008. Fluid Mechanics of Environmental Interfaces, Taylor \& Francis p.1-196.

36. Valantinas, J.; Kančelkis, D. 2011. Speeding-up Image Encoding Times in the SPIHT Algoritm, Information Technology and Control 40(1): 7-12. https://doi.org/10.5755/j01.itc.40.1.187.

37. Vaidelienè, A.; Tervydis, P. 2013.Measurement of Air Bubbles Concentrations in the Water by Means Digital Image Processing, Elektronika ir Elektrotechnika (Electronics and Electrical Engineering 19(4): 77-80. https://doi.org/10.5755/j01.eee.19.4.1846.

38. Mrak, M.; Grgic, S.; Grgic, M. 2003. Picture quality measures in image compression systems, Proc. Of IEEE EUROCON'2003 - Ljublijana, Slovenia, 1: 233-236. https://doi.org/10.1109/EURCON.2003.1248017.

39. Vysniauskas, V. 2006. Triangle based Image Magnification, Elektronika ir Elektrotechnika (Electronics and Electrical Engineering) 6(70): 45-48.

A. Vaidelienè, G. Miliauskas

\section{INVESTIGATION OF WATER AERATION BASED ON DIGITAL IMAGE PROCESSING}

$\mathrm{S} \mathrm{u} \mathrm{m} \mathrm{m} \mathrm{a} \mathrm{r} \mathrm{y}$

This paper deals with physics of water aeration. Falling water flow produces air bubbles and water droplets mixture in the air-water interface. This mixture develops in the course of time. A new method of determination of amount of air entrained in water was presented. The method was based on digital image processing. Method allows determination of dynamics of air entrainment depending on several parameters of nozzle as well as on height of falling water flow.

Keywords: water droplets, digital image processing, water droplets, air bubbles, vertical water jet, digital camera.

Received November 20, 2017 Accepted June 14, 2018 